\title{
ANALISIS STRATEGI PEMASARAN WEB HOSTING PT SINGCAT NETWORK
}

\author{
Suryadiputra Liawatimena ${ }^{1}$; Andy Margono ${ }^{2}$ Yati $^{3}$
}

\begin{abstract}
The development of business hosting in Indonesia is getting quicker and promising, along with the technology development and usage of internet. This development is followed by more companies that compete in hosting industry. Because of that, an analysis to one of the companies having hosting sector, PT Singcat Network was conducted. The result of analysis shows that company has a good strength to use available opportunity. But, until now the company is still less aggressive in market approaching. Strategy formulation that appropriate is needed to expand the market and in order to be able to compete and become the leader in hosting sector.
\end{abstract}

Keywords: marketing strategies, web hosting

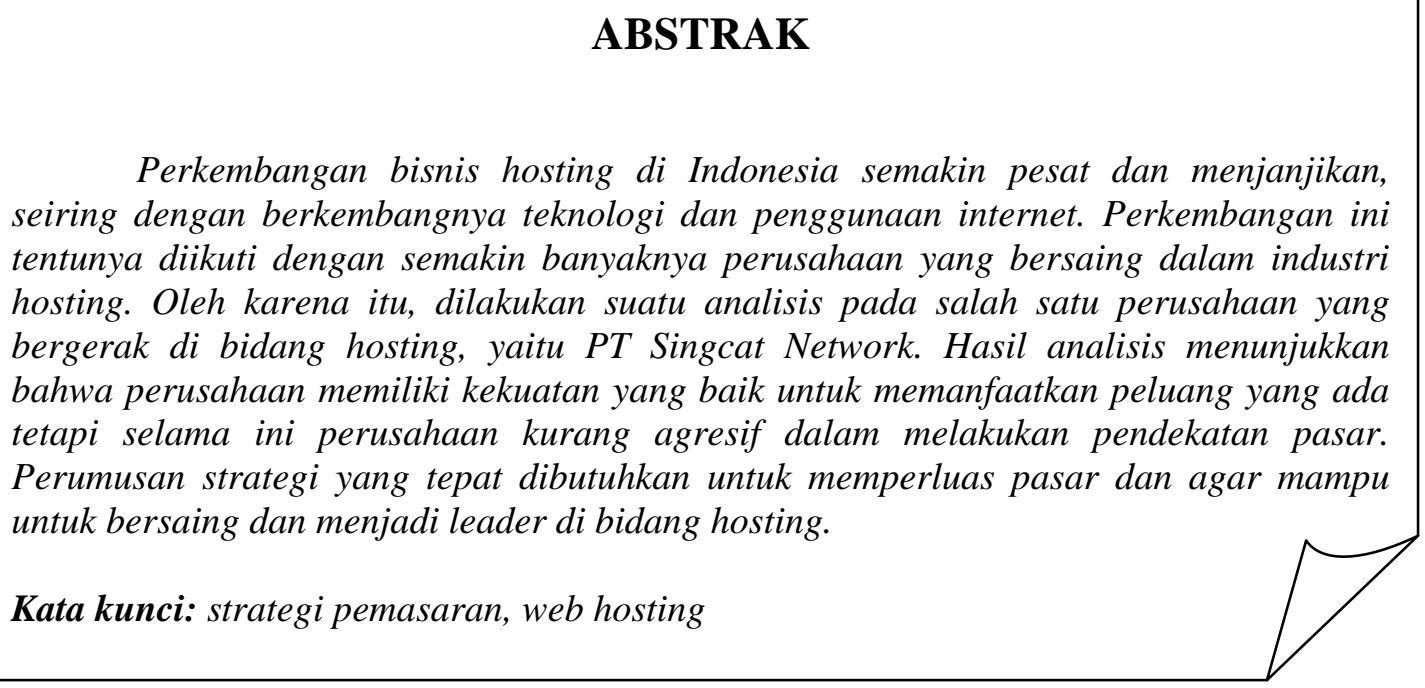

\footnotetext{
${ }^{1}$ Staf Pengajar Fakultas Ekonomi Jurusan Manajemen, UBiNus, Jakarta

2, 3 Mahasiswa Fakultas Ekonomi Jurusan Manajemen, UBiNus, Jakarta
} 


\section{PENDAHULUAN}

Kemajuan teknologi berupa internet telah berkembang pesat dan telah menjadi kebutuhan dalam menghadapi persaingan bisnis yang semakin ketat sehingga tidak dapat dipungkiri lagi peranan internet untuk keberlangsungan atau hidup matinya perusahaan dalam bersaing. Kelebihan yang ditawarkan oleh internet membuat perusahaan mampu berkesempatan untuk melakukan promosi selama 24 jam dan biaya yang diperlukan pun tidak terlalu mahal dalam perawatan dan pengoperasiannya. Hal itu mampu memberikan kesempatan memperluas pasar karena pada perkembangan jaman sekarang ini semakin banyak orang yang menggunakan fasilitas internet untuk mencari informasi yang dibutuhkan dalam segala hal.

PT Singcat Network adalah sebuah perusahaan jasa yang menyelenggarakan hosting untuk perusahaan yang mencari solusi hosting dengan biaya yang terjangkau dengan layanan prima. Peluang untuk mencari pelanggan baru ataupun untuk tetap dapat berhubungan dengan para konsumen dengan cara yang praktis, mudah, dan mampu meningkatkan pelayanan dan tetap keep in touch dengan konsumen lama yang pernah memakai jasa yang pernah digunakan pada PT Singcat Network perlu dijaga. Hal itu karena hal tersebut secara langsung atau tidak langsung dapat meningkatkan penghasilan dengan adanya pelanggan baru dan mampu mengikat loyalitas dari konsumen lama, dan membuatnya membeli jasa dari perusahaan dimasa yang akan datang. Konsumen yang loyal akan dengan sendirinya memberikan promosi mengenai produk perusahaan kepada teman dan kerabat dekatnya, bila mereka merasa puas dalam hal kualitas dan pelayanan yang diberikan.

\section{PEMBAHASAN}

\section{Strategi}

Menurut Chandler (Rangkuti, 2000:3), strategi merupakan alat untuk mencapai tujuan perusahaan dalam kaitannya dengan tujuan jangka panjang, program tindak lanjut, serta prioritas alokasi sumber daya. Definisi strategi yang dikemukakan oleh Chandler menyebutkan bahwa "Strategi adalah tujuan jangka panjang dari suatu perusahaan serta pendayagunaan dan alokasi semua sumber daya yang penting untuk mencapai tujuan tersebut”. Pemahaman yang baik mengenai konsep strategi dan konsep lain yang berkaitan, sangat menentukan suksesnya strategi yang disusun. Konsep tersebut adalah sebagai berikut.

Pertama, Distinctive Competence, yaitu tindakan yang dilakukan oleh perusahaan agar dapat melakukan kegiatan lebih baik dibandingkan dengan pesaingnya. Suatu perusahaan yang memiliki kekuatan yang tidak mudah ditiru oleh perusahaan pesaing 
dipandang sebagai perusahaan yang memiliki Distinctive Competence. Distinctive Competence menjelaskan kemampuan spesifik suatu organisasi. Menurut Day dan Wensley (Rangkuti, 2000:5), identifikasi distinctive competence dalam suatu organisasi, meliputi keahlian tenaga kerja dan kemampuan sumber daya. Dua faktor tersebut menyebabkan perusahaan ini dapat lebih unggul dibandingkan dengan pesaingnya. Keahlian sumber daya manusia yang tinggi muncul dari kemampuan membentuk fungsi khusus yang lebih efektif dibanding pesaing. Dengan memiliki kemampuan melakukan riset pemasaran yang lebih baik, perusahaan dapat mengetahui secara tepat semua keinginan konsumen sehingga dapat menyusun strategi pemasaran yang lebih baik dibandingkan dengan pesaingnya. Semua kekuatan tersebut dapat diciptakan melalui penggunaan seluruh potensi sumber daya yang dimiliki perusahaan. Semua itu merupakan keunggulan yang dapat diciptakan untuk memperoleh keuntungan dari pasar dan mengalahkan pesaing

Kedua, Competitive Advantage adalah kegiatan spesifik yang dikembangkan oleh perusahaan agar lebih unggul dibandingkan dengan pesaingnya. Keunggulan bersaing disebabkan oleh pilihan strategi yang dilakukan perusahaan untuk merebut peluang pasar. Menurut Porter, ada tiga strategi yang dapat dilakukan perusahaan untuk memperoleh keunggulan bersaing, yaitu Cost leadership, perusahaan dapat lebih memperoleh keunggulan bersaing yang lebih tinggi dibandingkan pesaingnya jika dapat memberikan harga jual yang lebih murah daripada harga yang diberikan oleh pesaingnya dengan nilai/kualitas produk yang sama. Harga jual yang lebih rendah dapat dicapai oleh perusahaan tersebut karena memanfaatkan skala ekonomis, efisiensi produksi, penggunaan teknologi, dan sebagainya; Diferensiasi, perusahaan dapat melakukan strategi diferensiasi dengan menciptakan persepsi terhadap nilai tertentu pada konsumennya; Fokus, strategi fokus juga dapat diterapkan untuk memperoleh keunggulan bersaing sesuai dengan segmentasi dan pasar sasaran yang diharapkan.

\section{Pemasaran}

Menurut Kotler (2001:7), pemasaran adalah proses sosial dimana individu dan kelompok mendapatkan yang mereka butuhkan dan inginkan dengan melakukan penciptaan, penawaran, atau pertukaran nilai dengan pihak lain. Manajemen pemasaran merupakan analisis, perencanaan, implementasi, dan pengendalian program yang dirancang untuk menciptakan, membangun, dan memelihara pertukaran yang menguntungkan dengan pembeli sasaran untuk mencapai tujuan perusahaan.

Konsep pemasaran adalah gagasan sederhana tetapi sangat penting. Konsep pemasaran berarti bahwa organisasi mengarahkan semua upayanya untuk memenuhi kebutuhan pelanggan dan berlaba. Konsep pemasaran masyarakat menyatakan bahwa tugas organisasi adalah menentukan kebutuhan, keinginan, dan minat pasar sasaran dan memberi kepuasan yang diinginkan secara lebih efektif dan efisien dibandingkan pesaing dengan tetap memelihara dan meningkatkan kesejahteraan masyarakat. 


\section{Strategi Pemasaran}

Menurut McCarthy dan Perreault (1996:32), strategi pemasaran adalah "gambaran besar" yang memperlihatkan hal yang akan dilakukan perusahaan dalam pasar tertentu. Ada dua bagian yang diperlukan, yaitu Pasar target, sekelompok konsumen yang agak homogen (serupa) yang akan dihimbau perusahaan dan Bauran pemasaran, yaitu sejumlah variabel yang dapat dikendalikan yang digabungkan perusahaan untuk memenuhi kebutuhan kelompok target. Perencanaan strategi pemasaran berarti upaya menemukan peluang menarik dan penyusunan strategi pemasaran yang berlaba. Strategi pemasaran merincikan target dan bauran pemasaran (Marketing Mix) yang berkaitan.

Strategi pemasaran itu terdiri dari campuran unsur yang disebut bauran pemasaran (marketing mix) atau 4P, yaitu Price, Promotion, Place, dan Product. Pertama, Produk (product): Terdiri dari keragaman produk, kualitas, desain, ciri, merek, kemasan, ukuran, dan lain-lain. Kedua, Harga (price): Terdiri dari daftar harga, potongan harga, periode pembayaran, dan persyaratan kredit. Ketiga, Promosi (promotion): Terdiri dari promosi penjualan, periklanan, tenaga penjualan, kehumasan, dan pemasaran langsung. Keempat, Tempat (place): Terdiri dari saluran pemasaran, cakupan pasar, pengelompokan, persediaan, dan transportasi

\section{Web Hosting}

Web hosting adalah penempatan homepage pelanggan pada salah satu server milik penyedia jasa dengan membayarkan sejumlah biaya yang telah ditentukan untuk mendapatkan fasilitas yang disediakan oleh penyedia jasa. Dengan jasa web hosting, seseorang dapat memiliki situs web dengan alamat yang diinginkan, seperti www.namaperusahaan.com untuk memperkenalkan nama perusahaan ke seluruh dunia ataupun transaksi internet lainnya. Penempatan situs perusahaan di internet memerlukan investasi perangkat keras, perangkat lunak, serta infrastruktur jaringan komputer yang sangat kompleks dan mahal yang dapat mencapai puluhan ribu dolar Amerika. Meskipun demikian, perusahaan dapat menyewa web space, bandwidth. dan layanan tambahan lainnya dari pihak ketiga (outsourcing) sehingga tidak memerlukan investasi yang mahal. Terdapat dua jenis hosting pada sistem operasi, yaitu hosting pada sistem operasi Windows dan Unix. Pada sistem Unix, sistem operasinya dianggap lebih serta cepat karena mendukung open-source program freeware dan shareware. Web hosting berbasis Unix sangat baik bagi pengguna yang menginginkan tingkat sekuritas yang tinggi.

\section{Analisis SWOT}

Analisis SWOT (Rangkuti, 2000:18) adalah identifikasi berbagai faktor secara sistematis untuk merumuskan strategi perusahaan. Analisis ini didasarkan pada logika yang dapat memaksimalkan kekuatan (strenghts) dan peluang (opportunities) namun secara bersamaan dapat meminimalkan kelemahan (weakness) dan ancaman (threats). Proses pengambilan keputusan strategis selalu berkaitan dengan pengembangan misi, 
tujuan strategi, dan kebijakan perusahaan. Dengan demikian, perencanaan strategis (strategic planner) harus menganalisis faktor strategis perusahaan (kekuatan, kelemahan, peluang, dan ancaman) dalam kondisi yang ada saat ini. Hal ini disebut dengan Analisis situasi. Model paling populer untuk analisis situasi adalah analisis SWOT.

\section{Matriks IFAS}

Matriks ini digunakan untuk mengevaluasi faktor internal perusahaan yang berhubungan dengan kekuatan dan kelemahan yang dianggap penting. Data dan informasi aspek internal dapat diperoleh dari fungsional perusahaan, seperti aspek manajemen, keuangan, SDM, pemasaran, sistem informasi dan produksi, serta operasi. Tahapan kerjanya adalah sebagai berikut. Pertama, menentukan faktor kekuatan dan kelemahan perusahaan. Kedua, memberi bobot masing-masing faktor tersebut menggunakan teknik perbandingan berpasangan. Adapun bobot pengaruh yang diberikan adalah 4 : Sangat besar; 3 : Besar; 2 : Sedang; 1 : Kecil. Ketiga, mengalikan bobot dengan rating untuk memperoleh faktor pembobotan. Keempat, menjumlah skor pembobotan untuk memperoleh total pembobotan bagi perusahaan yang bersangkutan. Nilai total menunjukkan bagaimana perusahaan bereaksi terhadap faktor strategis internalnya. Skor total dapat digunakan untuk perbandingan dengan perusahaan lain dalam industri yang sama.

\section{Matriks EFAS}

Digunakan untuk mengevaluasi faktor eksternal perusahaan berkaitan dengan peluang dan ancaman bagi perusahaan. Tahapan kerja matriks EFAS sama dengan matriks IFAS.

\section{Matriks SWOT}

Matriks ini digunakan setelah menentukan IFAS dan EFAS, dapat menggambarkan dengan jelas bagaimana peluang dan ancaman eksternal yang dihadapi dapat disesuaikan dengan kekuatan dan kelemahan yang dimiliki. 
Tabel 1 Matriks SWOT

\begin{tabular}{lll}
\hline \multicolumn{1}{c}{ IFAS } & Strenghts (S) & Weakness (W) \\
\hline EFAS & $\begin{array}{l}\text { Tentukan faktor kekuatan } \\
\text { internal }\end{array}$ & Tentukan faktor kelemahan internal \\
\hline Opportunities (O) & SO Strategies & WO Strategies \\
\hline $\begin{array}{l}\text { Tentukan faktor peluang } \\
\text { eksternal }\end{array}$ & $\begin{array}{l}\text { Ciptakan strategi yang } \\
\text { menggunakan kekuatan } \\
\text { untuk memanfaatkan } \\
\text { peluang }\end{array}$ & $\begin{array}{l}\text { Ciptakan strategi yang meminimalkan } \\
\text { kelemahan untuk memanfaatkan } \\
\text { peluang }\end{array}$ \\
\hline Threats (T) & ST Strategies & WT Strategies \\
\hline $\begin{array}{l}\text { Tentukan faktor ancaman } \\
\text { eksternal }\end{array}$ & $\begin{array}{l}\text { Ciptakan strategi yang } \\
\text { menggunakan kekuatan } \\
\text { untuk mengatasi ancaman }\end{array}$ & $\begin{array}{l}\text { Ciptakan strategi yang meminimalkan } \\
\text { kelemahan dan menghindari ancaman }\end{array}$ \\
\hline
\end{tabular}

Sumber: Wheelen, 2002

\section{Permasalahan yang Dihadapi}

Hingga saat ini, PT Singcat Network belum mengetahui bagaimana respons pelanggan terhadap harga, layanan, kelengkapan paket, kemudahan, dan tingkat kepuasan yang diberikan oleh Singcat. Singcat juga belum memiliki strategi pemasaran yang tepat dan sesuai dengan kemampuan dan kondisi perusahaan saat ini.

\section{Usulan Pemecahan Masalah}

\section{Analisis Hasil Kuesioner}

Menyebarkan kuesioner dengan tujuan untuk mengetahui respons pelanggan terhadap Singcat. Kuesioner disebarkan kepada para pelanggan Singcat. Kuesioner terdiri dari 9 (sembilan) pertanyaan, 8 pertanyaan pilihan, dan 1 pertanyaan berupa komentar. Adapun hasil kuesioner terhadap 356 responden adalah sebagai berikut. Pertama, berapa lama anda sudah berlangganan pada Singcat? Hasil kuesioner menunjukkan seperti terlihat pada Gambar 1. 


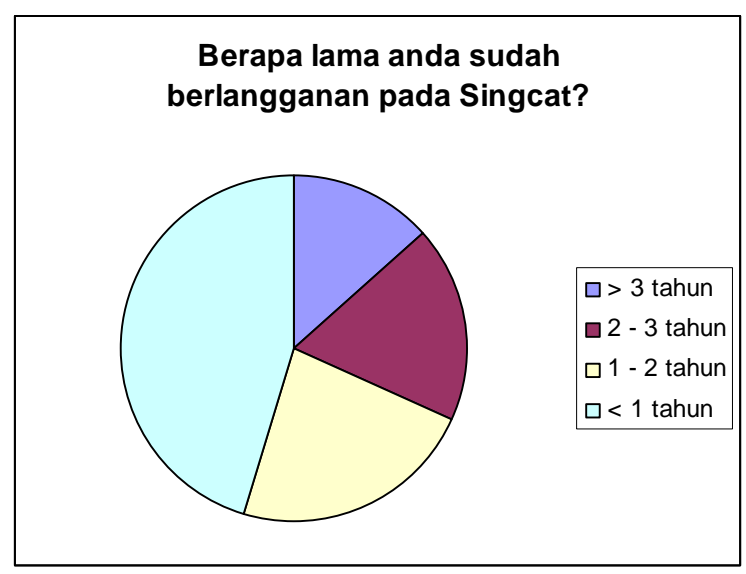

Gambar 1 Hasil Kuesioner Pertanyaan Nomor 1

Dari hasil tersebut dapat diambil simpulan bahwa sebanyak 47 orang responden $(13,2 \%)$ menjawab lebih dari 3 tahun, 66 orang (18,54\%) menjawab antara 2 sampai 3 tahun, 82 orang $(23,03 \%)$ menjawab antara 1 sampai 2 tahun, dan 161 orang (45,22\%) menjawab kurang dari 1 tahun.

Kedua, puaskah Anda dengan yang Anda dapatkan di Singcat sejauh ini? Hasil kuesioner menunjukkan seperti terlihat pada Gambar 2.

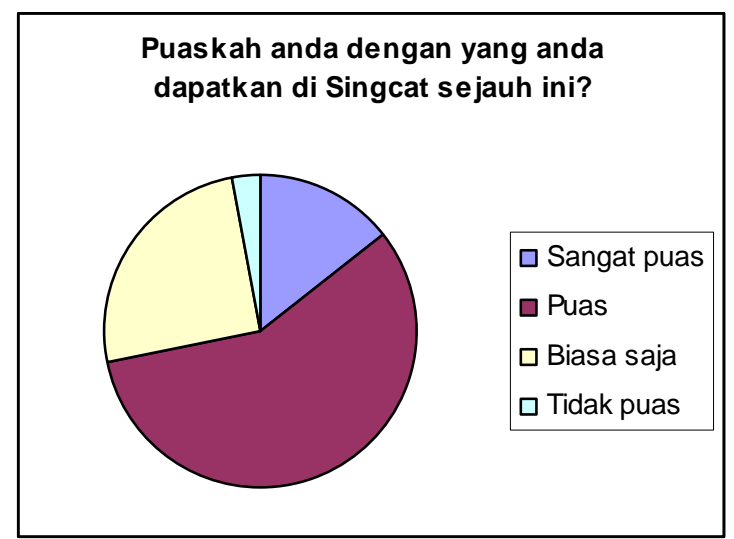

Gambar 2 Hasil Kuesioner Pertanyaan Nomor 2

Dari hasil tersebut dapat diambil simpulan bahwa sebanyak 51 orang responden (14,33\%) menjawab sangat puas, 204 orang (57,30\%) menjawab puas, 90 orang (25,28\%) menjawab biasa saja, dan 11 orang (3,09\%) menjawab tidak puas. 
Ketiga, darimana anda mengetahui mengenai Singcat? Hasil kuesioner menunjukkan seperti terlihat pada Gambar 3.

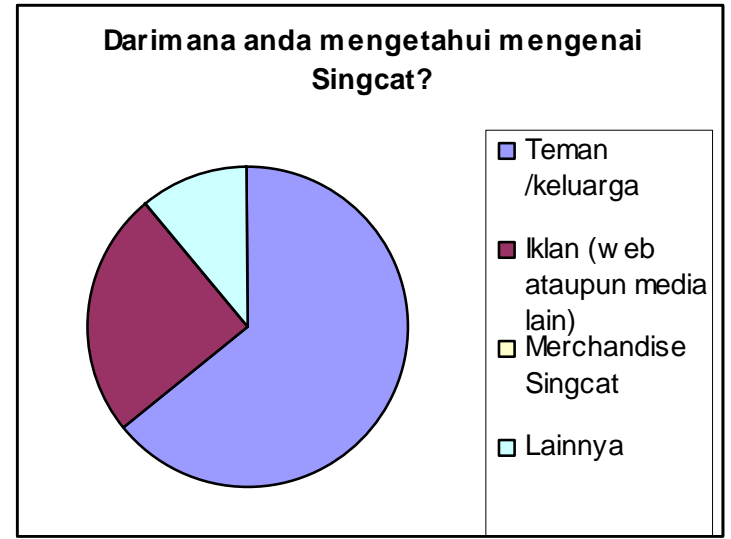

Gambar 3 Hasil Kuesioner Pertanyaan Nomor 3

Dari hasil tersebut dapat diambil simpulan bahwa sebanyak 228 orang responden $(63,87 \%)$ menjawab dari teman/keluarga, 89 orang (24,93\%) menjawab dari iklan, $0(0 \%)$ yang menjawab dari merchandise Singcat, dan 40 orang (11,2\%) menjawab dari bidang lainnya

Keempat, agaimana menurut Anda harga yang ditawarkan Singcat dibanding perusahaan lain, dengan paket yang sama/sejenis? Hasil kuesioner menunjukkan seperti terlihat pada Gambar 4.

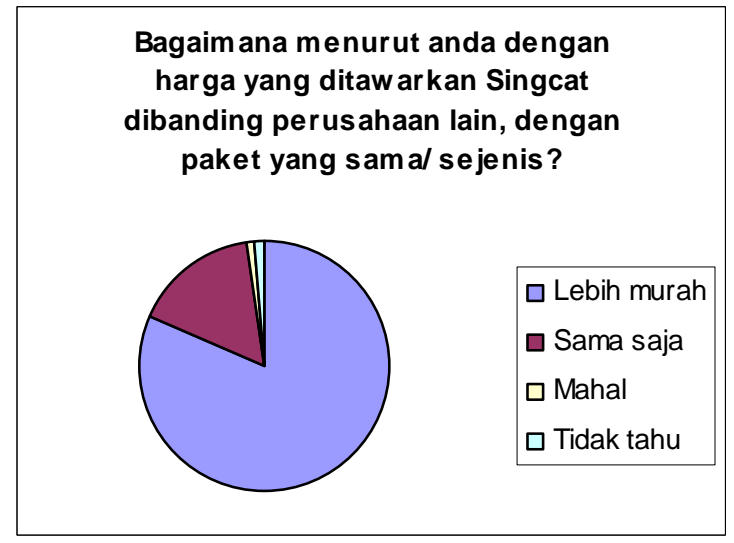

Gambar 4 Hasil Kuesioner Pertanyaan Nomor 4

Dari hasil tersebut dapat diambil simpulan bahwa sebanyak 288 orang responden (81,36\%) menjawab lebih murah dibanding perusahaan lain, 58 orang (16,38\%) menjawab sama saja, 3 orang $(0,85 \%)$ menjawab lebih mahal, dan 5 orang $(1,41 \%)$ menjawab tidak tahu. 
Kelima, bagaimana dengan layanan yang diberikan oleh Singcat? Hasil kuesioner menunjukkan seperti terlihat pada Gambar 5.

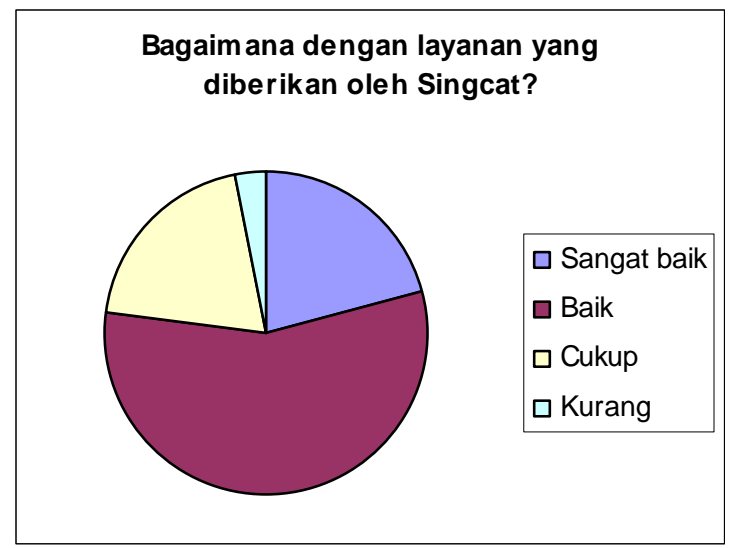

Gambar 5 Hasil Kuesioner Pertanyaan Nomor 5

Dari hasil tersebut dapat diambil simpulan bahwa sebanyak 74 orang responden (20,85\%) menjawab sangat baik, 199 orang (56,06\%) menjawab baik, 71 orang (20\%) menjawab cukup, dan 11 orang menjawab kurang (3,10\%)

Keenam, bagaimana kelengkapan paket dan fasilitas yang ditawarkan oleh Singcat? Hasil kuesioner menunjukkan seperti terlihat pada Gambar 6.

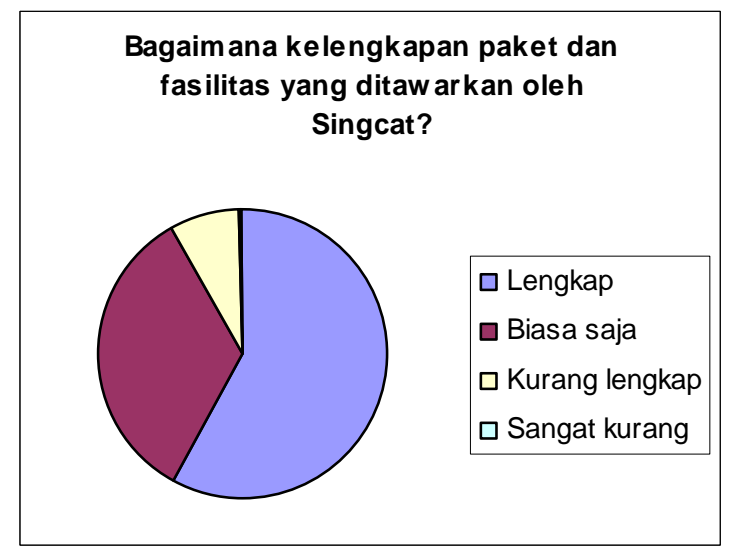

Gambar 6 Hasil Kuesioner Pertanyaan nomor 6

Dari hasil tersebut dapat diambil simpulan bahwa sebanyak 204 orang responden (57,79\%) menjawab lengkap, 121 orang (34,28\%) menjawab biasa saja, 27 orang (7,65\%) menjawab kurang lengkap, dan 1 orang $(0,28 \%)$ menjawab sangat kurang. 
Ketujuh, bagaimana dengan kemudahan yang didapat melalui website singcat.com? Hasil kuesioner menunjukkan seperti terlihat pada Gambar 7.

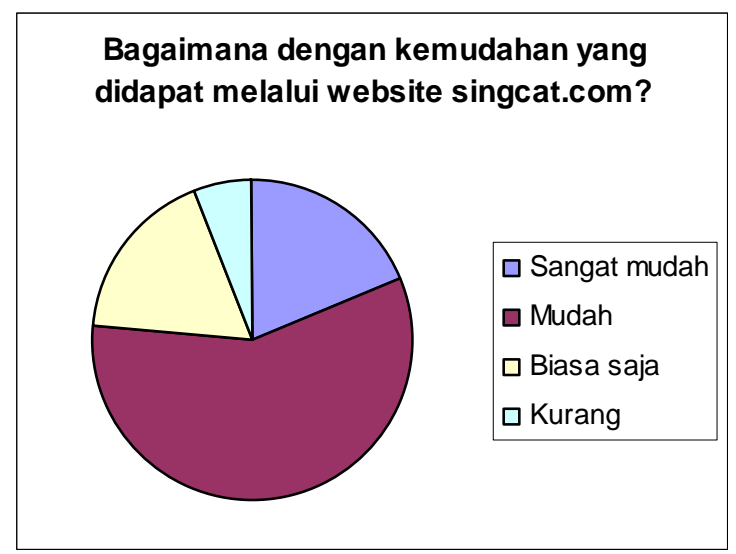

Gambar 7 Hasil Kuesioner Pertanyaan Nomor 7

Dari hasil tersebut dapat diambil simpulan bahwa sebanyak 67 orang responden (18,82\%) menjawab sangat mudah, 205 orang (57,58\%) menjawab mudah, 63 orang $(17,70 \%)$ menjawab biasa saja, 21 orang (5,90\%) menjawab kurang.

Kedelapan, berikan prioritas mengapa Anda memilih Singcat. Hasil kuesioner menunjukkan seperti terlihat pada Gambar 8.

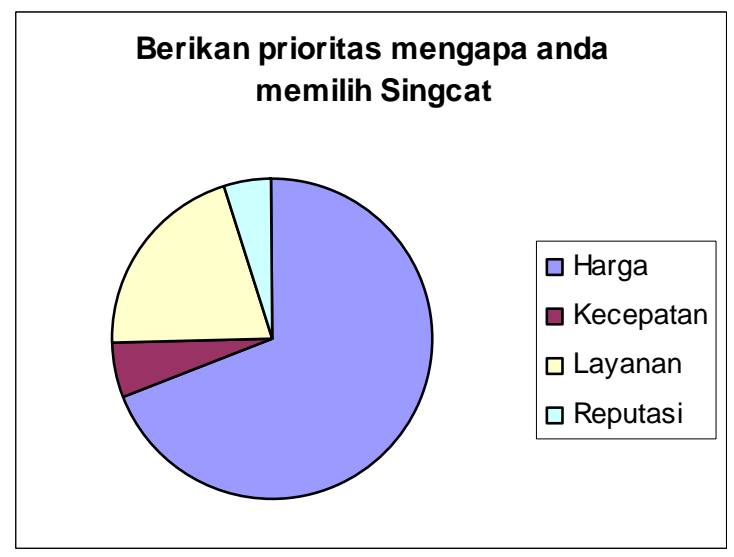

Gambar 8 Hasil Kuesioner Pertanyaan Nomor 8

Dari hasil tersebut dapat diambil simpulan bahwa sebanyak 246 orang responden (68,91\%) menjawab harga, 20 orang (5,60\%) menjawab kecepatan, 74 orang (20,73\%) menjawab layanan, dan 17 orang (4,76\%) menjawab reputasi. 
Dari pertanyaan kesembilan tentang apa yang diperlukan Singcat untuk ditingkatkan lagi, didapat amat banyak masukan berupa saran dan kritik dari para member untuk kemajuan Singcat. Antara lain, meningkatkan layanan customer service kepada pelanggan, mempertahankan harga yang murah, security, dan stabilitas dan lain-lain.

\section{Analisis SWOT}

Untuk merumuskan strategi pemasaran yang tepat bagi PT Singcat Network, dilakukan analisis SWOT untuk mengetahui keadaan lingkungan internal dan eksternal perusahaan, dan merumuskan strategi pemasaran web hosting yang tepat dan sesuai dengan keadaan lingkungan perusahaan.

Tabel 2 Matriks IFAS PT Singcat Network

\begin{tabular}{cllccc}
\hline No. & Faktor Internal & Bobot & Score & B * S \\
\hline 1 & S-1 & Harga yang kompetitif & 0.08 & 4 & 0.32 \\
2 & S-2 & Kestabilan server & 0.21 & 3 & 0.63 \\
3 & S-3 & Customer Service yang personalize & 0.16 & 3 & 0.48 \\
4 & S-4 & Hosting gratis bagi lembaga pendidikan & 0.03 & 2 & 0.06 \\
5 & S-5 & Biaya operasional rendah & 0.04 & 2 & 0.08 \\
Total & stenghts & & & $\mathbf{1 . 5 7}$ \\
6 & W-1 & Kurangnya media promosi & 0.07 & 3 & 0.21 \\
7 & W-2 & Tidak memiliki strategi marketing yang agresif & 0.16 & 4 & 0.64 \\
8 & W-3 & Sumber daya manusia yang terbatas & 0.06 & 2 & 0.12 \\
9 & W-4 & Member Singcat saat ini mayoritas berskala kecil & 0.04 & 2 & 0.08 \\
10 & W-5 & Modal kecil & 0.16 & 2 & 0.32 \\
\hline \multicolumn{7}{l}{ Total } & Weakness & & & $\mathbf{1 . 3 7}$ \\
\hline \multicolumn{7}{l}{ Total } & & & & $\mathbf{2 . 9 4}$ \\
\hline
\end{tabular}

Tabel 3 Matriks EFAS PT Singcat Network

\begin{tabular}{|c|c|c|c|c|c|}
\hline No. & & \begin{tabular}{|l|} 
Faktor Eksternal \\
\end{tabular} & Bobot & Score & B * S \\
\hline 1 & $\mathrm{O}-1$ & Bisnis hosting adalah bisnis yang sangat menjanjikan & 0.06 & 3 & 0.18 \\
\hline 2 & $\mathrm{O}-2$ & Free set-up menjadi pertimbangan utama konsumen & 0.07 & 2 & 0.14 \\
\hline 3 & O-3 & Dukungan perkembangan IT & 0.10 & 4 & 0.40 \\
\hline 4 & $\mathrm{O}-4$ & Kebutuhan akan website pribadi/organisasi semakin luas & 0.13 & 3 & 0.39 \\
\hline 5 & O-5 & $\begin{array}{l}\text { Rekomendasi Mouth to Words membuktikan kualitas } \\
\text { produk }\end{array}$ & 0.20 & 3 & 0.60 \\
\hline \multicolumn{5}{|c|}{ Total opportunities } & 1.71 \\
\hline 6 & $\mathrm{~T}-1$ & $\begin{array}{l}\text { Persaingan dari perusahaan hosting lain yang skalanya } \\
\text { lebih besar }\end{array}$ & 0.06 & 4 & 0.24 \\
\hline 7 & $\mathrm{~T}-2$ & \begin{tabular}{|l|l} 
Brand image pesaing yang lebih kuat &
\end{tabular} & 0.15 & 2 & 0.30 \\
\hline 8 & $\mathrm{~T}-3$ & Marketing pesaing yang lebih agresif & 0.14 & 4 & 0.56 \\
\hline 9 & $\mathrm{~T}-4$ & Hosting gratisan & 0.05 & 1 & 0.05 \\
\hline 10 & $\mathrm{~T}-5$ & Pendatang baru yang potensial & 0.05 & 3 & 0.15 \\
\hline \multicolumn{5}{|c|}{ Total Threats } & 1.30 \\
\hline \multicolumn{5}{|c|}{ Total } & 3.01 \\
\hline
\end{tabular}


Tabel 4 Matriks IE Hasil Penelitian

\section{Total Nilai EFAS Berbobot}

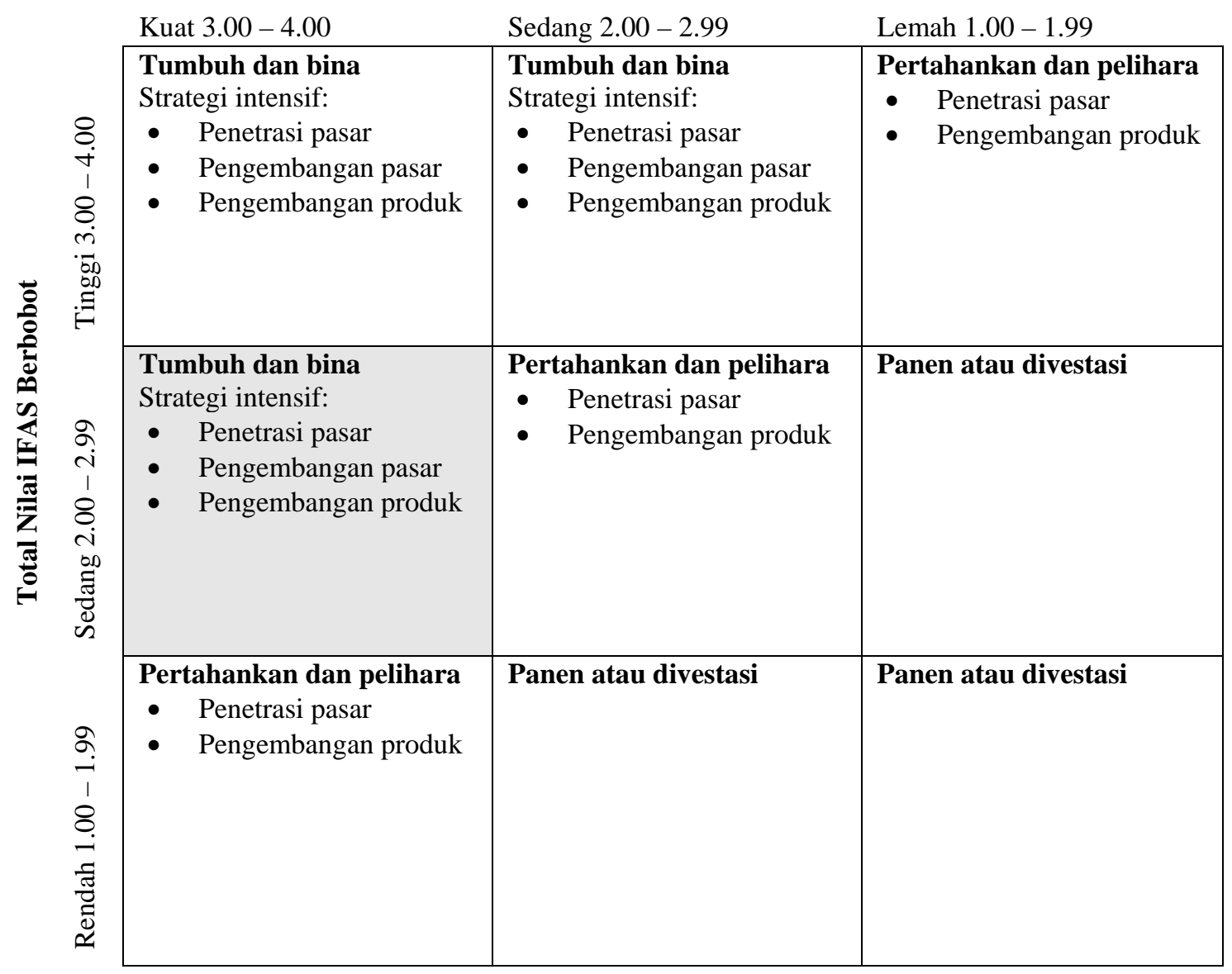




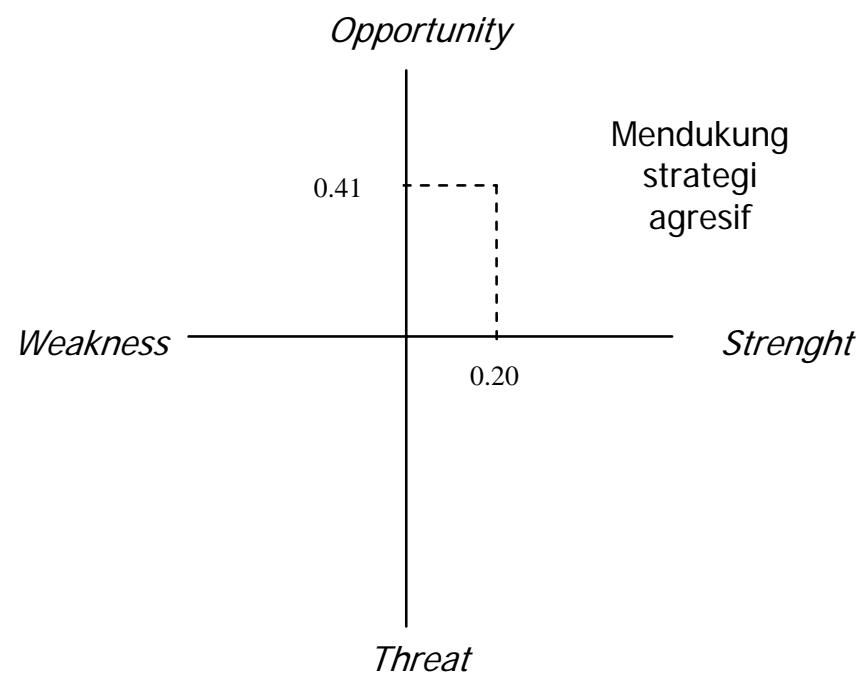

Gambar 9 Posisi Relatif PT Singcat Network

Tabel 5 Matriks SWOT Hasil Penelitian

\begin{tabular}{|c|c|c|}
\hline & \begin{tabular}{|l} 
Opportunities $(\mathbf{O})$ \\
1.
\end{tabular} & \begin{tabular}{|l|} 
Threats $\mathbf{( T )}$ \\
Persaingan dari perusahaan \\
\\
hosting lain yang skalanya \\
lebih besar \\
Brand image pesaing yang \\
lebih kuat \\
Marketing pesaing yang lebih \\
agresif \\
.
\end{tabular} \\
\hline \begin{tabular}{|ll} 
Strenghts (S) \\
1. & Harga yang \\
& kompetitif \\
2. & Kestabilan server \\
3. & Customer Service \\
& yang personalize \\
4. & Hosting gratis bagi \\
& lembaga pendidikan \\
5. & Biaya operasional \\
& rendah
\end{tabular} & \begin{tabular}{|l} 
Strategi SO \\
1. \\
Menonjolkan keunggulan \\
kompetitif dari segi harga dan fitur \\
yang ditawarkan PT. Singcat \\
dibandingkan dengan perusahaan \\
lain. \\
2. \\
Merencanakan strategi marketing \\
yang lebih agresif melalui \\
pelayanan member yang \\
personalize sahingga selain \\
memperoleh member baru dari \\
rekomendasi member lama, \\
Singcat juga dapat \\
mengembangkan bisnis lebih luas \\
dan cepat.
\end{tabular} & $\begin{array}{l}\text { Strategi ST } \\
\text { Menggunakan kekuatan } \\
\text { untuk mengatasi ancaman } \\
\text { terhadap perusahaan. } \\
\text { Menciptakan brand image. }\end{array}$ \\
\hline
\end{tabular}




\begin{tabular}{|c|c|c|}
\hline Weaknesses (W) & Strategi WO & Strategi WT \\
\hline \multicolumn{3}{|l|}{ 1. Kurangnya media } \\
\hline promosi & meminimalkan kelemahan melalui & perusahaan dan strategi \\
\hline 2. Tidak memiliki & pemanfaatan peluang yang ada. & defensif yang diarahkan \\
\hline strategi marketing & Peningkatan sumber daya manusia & untuk mengurangi \\
\hline yang agresif & & kelemahan internal dan \\
\hline 3. Sumber daya manusia & & menghindari ancaman \\
\hline $\begin{array}{ll}\text { 4. } & \text { Memg terbatas } \\
\text { Member Singcat saat }\end{array}$ & & \\
\hline $\begin{array}{l}\text { 4. Member Singcat saat } \\
\text { ini mayoritas berskala }\end{array}$ & & \\
\hline kecil & & \\
\hline 5. Modal kecil & & \\
\hline
\end{tabular}

\section{PENUTUP}

Berdasarkan analisis yang telah dilakukan, dapat diperoleh simpulan sebagai berikut. Pertama, strategi pemasaran yang telah berjalan pada PT Singcat Network sudah berjalan dengan baik, dibuktikan dengan hasil kuesioner dan sebanyak $71.63 \%$ pelanggan merasa puas dengan yang sudah didapatkan di Singcat. Kedua, PT Singcat Network memiliki kekuatan internal dan peluang baik yang dapat dimanfaatkan pada pengembangan strategi pemasaran yang agresif dan pengembangan bisnisnya. Strategi pemasaran web hosting yang tepat bagi Singcat adalah dengan mengarahkan promosi web www.singcat.com untuk menciptakan brand image yang kuat.

Adapun saran yang dapat diberikan kepada PT Singcat Network adalah sebagai berikut. Pertama, memperluas pasar dari segi jumlah konsumen agar mampu menjadi leader dibidang hosting dengan cara memperbanyak promosi melalui berbagai media. Kedua, menonjolkan keunggulan kompetitif dari segi harga dan fitur yang ditawarkan PT Singcat dibandingkan dengan perusahaan lain dalam strategi pemasaran yang akan datang. Ketiga, merencanakan strategi marketing yang lebih agresif melalui pelayanan member yang personalize sehingga selain memperoleh member baru dari rekomendasi member lama, Singcat juga dapat mengembangkan bisnis lebih luas dan cepat. 


\section{DAFTAR PUSTAKA}

Amor, Daniel. 2002. The e-business [r] evolution. New Jersey: Prentice Hall.

Andino Maseleno. 2003. "Kamus Istilah Komputer dan Informatika." Diakses 29 Agustus 2005 dari http://ilmukomputer.com.

Coupey, Eloise. 2001. Marketing and the Internet. New Jersey: Prentice Hall.

Chaffey, Dave, Richard Mayer, Kevin Johnston, and Fiona Ellis-Chadwick. 2000. Internet Marketing. Prentice Hall.

David, Fred R. 2004. Manajemen Strategis: Konsep. Edisi ketujuh. Jakarta: PT Prenhallindo.

Kertajaya, Hermawan. 2004. Marketing in Venus. Jakarta: PT Gramedia Pustaka Utama.

Kotler, Philip and Gary Armstrong. 2001. Prinsip-Prinsip Pemasaran. Jilid 1 Edisi ke-8. Erlangga.

McCarthy, Jerome and William Perreault. 1996. Dasar-Dasar Pemasaran. Edisi ke-5. Jakarta: Erlangga.

Rangkuti, Freddy. 2000. Analisis SWOT Teknik Membedah Kasus Bisnis: Reorientasi Konsep Perencanaan Strategis untuk Menghadapi Abad 21. Jakarta: PT Gramedia Pustaka Utama.

Sugiyono. 2004. Metode Penelitian Bisnis. Cetakan ketujuh. Bandung: CV Alfabeta.

Tim SDM STIKOM Surabaya. 1997. Pengantar HTML. Diakses 29 agustus 2005 dari http://www.infokomputer.com/arsip/internet/0797/tutor/tutorial1.shtml

Turban, Efraim, David King, Jae Lee, dan Dennis Viehland. 2004. Electronic Commerce: A Managerial Perspective. USA: Prentice Hall.

Wheelen, Thomas L. dan J. David Hunger. 2002. Strategic Management and Business Policy. USA: Prentice Hall. 